\title{
Dose Estimation of the BNCT Water Phantom Based on MCNPX Computer Code Simulation
}

\author{
Amanda Dhyan Purna Ramadhani ${ }^{1 *}$, Susilo ${ }^{1}$, Irfan Nurfatthan ${ }^{2}$, Yohannes Sardjono ${ }^{3}$, Widarto ${ }^{3}$, Gede Sutresna \\ Wijaya $^{3}$, Isman Mulyadi Triatmoko ${ }^{3}$ \\ ${ }^{1}$ Department of Physics, Mathematics and Natural Science Faculty, State University of Semarang. Jalan Taman Siswa, Sekaran, Gunungpati, Kota \\ Semarang, Indonesia \\ ${ }^{2}$ Department of Nuclear Engineering Universitas Gadjah Mada, Jl. Grafika No.2, Senolowo, Sinduadi, Kec. Mlati, Kabupaten Sleman, Daerah \\ Istimewa Yogyakarta, Yogyakarta and 55281, Indonesia \\ ${ }^{3}$ Centre of Accelerator Science and Technology,National Nuclear Energy Agency, Jalan Babarsari Kotak Pos 6101 ykbb, Yogyakarta, Indonesia
}

\section{ARTICLE INFO}

\section{Article history:}

Received: 20 February 2020

Received in revised form: 16 March 2020

Accepted: 17 March 2020

Keywords:

BNCT

Dose

Cancer

Water Phantom

MCNPX

\begin{abstract}
A B S T R A C T
Cancer is a malignant tumor that destroys healthy cells. Cancer treatment can be done by several methods, one of which is BNCT. BNCT uses ${ }^{10} \mathrm{~B}$ target which is injected into the human body, then it is irradiated with thermal or epithermal neutrons. Nuclear reaction will occur between boron and neutrons, producing alpha particle and lithium7. The dose is estimated by how much boron and neutron should be given to the patient as a sum of number of boron, number of neutrons, number of protons, and number of gamma in the reaction of the boron and neutron. To calculate the dose, the authors simulated the reaction with Monte Carlo N Particle-X computer code. A water phantom was used to represent the human torso, as $75 \%$ of human body consists of water. Geometry designed in MCNPX is in cubic form containing water and a cancer cell with a radius of $2 \mathrm{~cm}$. Neutron irradiation is simulated as originated from Kartini research reactor, modeled in cylindrical form to represent its aperture. The resulting total dose rate needed to destroy the cancer cell in GTV is $2.0814 \times 10^{14}$ Gy.s $(76,38 \%)$ with an irradiation time of $1,4414 \times 10^{-13} \mathrm{~s}$. In PTV the dose is $5.2295 \times 10^{13}$ Gy.s $(19,19 \%)$ with irradiation time of $5.7367 \times 10^{-13} \mathrm{~s}$. In CTV, required dose is $1.1866 \times 10^{13}$ Gy.s $(4,35 \%)$ with an irradiation time of $2.5283 \times 10^{-12} \mathrm{~s}$. In the water it is $1.9128 \times 10^{11}$ Gy.s $(0,07 \%)$ with an irradiation time of $1,5684 \times 10^{-10} \mathrm{~s}$. The irradiation time is extremely short since the modeling is based on water phantom instead of human body.
\end{abstract}

\section{INTRODUCTION}

Cancer is a malignant tumor, which destroys the healthy cells of the body. Cancer cells become abnormal cells that grow more than they should. The process of cancer cells spreading in the body is called metastasis, and it can result in death of a person. Cancer cell can grow in any kind of tissue, from skin tissue to important organs such as brain

"Corresponding author. Tel./Fax.: +62 88215250571

E-mail: amandadhypr@gmail.com

DOI: $10.17146 / \mathrm{tdm} .2020 .22 .1 .5780$ and lungs. To exacerbate the threat, cancer cell can spread from one tissue to another tissue [1].

There are several methods to treat cancer, such as surgery, chemotherapy, and radiotherapy. Every method has its specification, benefit, and risk. The surgical method is done by removing the cancerous tissue inside the body. This method leaves marks in body, since to reach the cancerous cell, surgical operation must be performed. In this method, the normal tissue may be removed along with the cancer tissue, or possibly not all cancerous tissue is removed during the process. The remaining 
cancerous tissue can therefore still grows and destroys the normal tissues on its surrounding. Chemotherapy is a type of cancer therapy that uses drugs. The drugs are delivered by injection into the vein or swallowed in pill form. Chemotherapy works to slow the growth of the cancer cells [1].

Another type of cancer therapy is radiotherapy. Radiotherapy uses particle of high-energy waves such as X-ray to kill the cancer cell. It works by damaging the DNA cells, and thereby causing the cell to die [2]. Radiotherapy usually uses the radiation in for of $\mathrm{X}$-ray, gamma ray, or other charged particles that possesses high energy, and it also has a risk in normal tissues [3]. Radiotherapy utilizes ionization properties generated by radiation sources in areas exposed to radiation. Radiation sources either be internal or external [4].

BNCT is a branch of radiotherapy that uses boron-10 isotope to capture neutrons [4]. This kind of radiotherapy is applied to the human body in a certain period of time instead of daily. Each person can get a personalized dose. BNCT works when the boron-10 carrier is injected into the body and then irradiated with neutrons. The reaction produces alpha and gamma energy along with lithium-7.

To apply the therapy to the patient, the dose given must first be estimated. This must be performed to maintain the safety of the patient. Nevertheless, applying the estimation directly is not necessarily safe to the patient of importance. Therefore, it must be applied to a phantom. One of the phantoms to be used is in form of water phantom, because human torso consists of about $75 \%$ water. Thus, the water phantom can represent the human torso [5].

\section{THEORY}

\subsection{Boron Neutron Capture Cancer Therapy}

Boron neutron capture therapy (BNCT) is a binary cancer treatment modality that involves the selective accumulation of boron-10 carriers in tumors, followed by irradiation with a thermal or epithermal neutron beam [6]. BNCT works selectively to reach the target cell. It was introduced by G. L. Locher in 1936. BNCT has the possibility to selectively target a cancerous cell that was given boron-10 while avoid damaging normal cell. Boron10 is non-toxic to the body, and a non-radioactive material which absorbs thermal neutrons which results in nuclear reaction of $10 \mathrm{~B}(\mathrm{n}, \alpha) 7 \mathrm{Li}$ [7].

BNCT is a two-step procedure: (1) The patient is injected with a tumor-localizing drug containing boron, and (2) the target volume is irradiated with thermal or epithermal neutrons. In this therapy, the following nuclear reaction is used:

$$
\begin{aligned}
{ }^{10} \mathrm{~B}+n & \rightarrow{ }^{7} \mathrm{Li}+\alpha+2.79 \mathrm{MeV}(6.1 \%) \\
& \rightarrow{ }^{7} \mathrm{Li}+\alpha+2.79 \mathrm{MeV}(93.9 \%) \\
& \searrow \quad{ }^{7} \mathrm{Li}+\gamma+0.48 \mathrm{MeV}
\end{aligned}
$$

The ranges of the $\alpha$ and the Li-7 particles generated in this reaction are approximately 8 and 5 $\mu \mathrm{m}$ in tissue. [8]

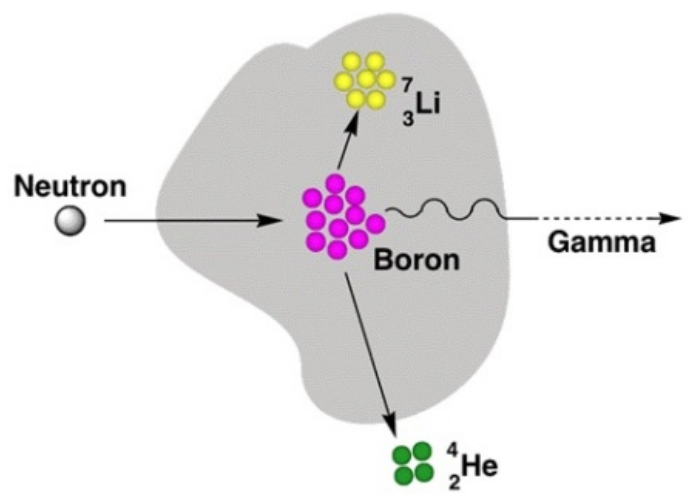

Figure 1. Schematic interaction between Boron and Neutron

Table 1. IAEA recommendation value of air beam-port

\begin{tabular}{|c|c|}
\hline $\begin{array}{c}\text { BNCT beam port } \\
\text { parameter }\end{array}$ & Limit \\
\hline$\Phi_{\text {epi }}\left(\mathrm{n} / \mathrm{cm}^{2} . \mathrm{sec}\right)$ & $\geq 10^{9}$ \\
\hline$\Phi_{\mathrm{th}} / \phi_{\mathrm{epi}}$ & $\leq 0.05$ \\
\hline $\mathrm{D}_{\mathrm{f}} / \phi_{\mathrm{epi}}\left(\mathrm{Gy} \mathrm{cm}^{2} / \mathrm{n}\right)$ & $\leq 2.0 \mathrm{E}-13$ \\
\hline $\mathrm{D}_{\Upsilon} / \phi_{\text {epi }}(\mathrm{Gy} \mathrm{cm} / \mathrm{n})$ & $\leq 2.0 \mathrm{E}-13$ \\
\hline $\mathrm{J}_{\mathrm{epi}} / \phi_{\mathrm{epi}}$ & $\geq 0.7$ \\
\hline$\Phi_{\text {th }}$ energy range & $\mathrm{E}<0.5 \mathrm{eV}$ \\
\hline$\Phi_{\text {epi }}$ energy range & $0.5 \mathrm{eV} \leq \mathrm{E} \leq 10 \mathrm{keV}$ \\
\hline$\Phi_{\mathrm{f}}$ energy range & $\mathrm{E}>10 \mathrm{keV}$ \\
\hline
\end{tabular}
parameter for the epithermal BNCT and the corresponding neutron beam energy limits [9]

where:

$\phi_{\text {epi }}$ is epithermal neutron flux

$\phi_{\text {th }}$ is thermal neutron flux,

$\phi_{\mathrm{f}}$ is the fast neutron flux,

$\mathrm{J}_{\text {epi }}$ is the epithermal neutron current,

$\mathrm{D}_{\mathrm{f} /} \phi_{\mathrm{epi}}$ is the fast neutron dose per epithermal neutron flux or "specific fast neutron dose"

$\mathrm{D}_{\Upsilon} / \phi_{\text {epi }}$ is the gamma dose per epithermal neutron flux or "specific gamma dose" [10]

The advantage of BNCT is that the boron at a certain concentration is non-toxic. Only the tissue located around the cancerous tissue is exposed to the effect of neutron irradiation and boron-10 needs to be considered. Another reason is that boron-10 has a greater thermal neutron uptake than any other element in the body. 
Table 2. Comparison of Mid-Thermal Neutron Capture Views Multiple Elements [11]

\begin{tabular}{ccc}
\hline Element & Mass (\%) & $\begin{array}{c}\text { Cross Section } \\
\text { (barns) }\end{array}$ \\
\hline Hydrogen & 10.5 & 32.945 \\
Oxygen & 63.5 & 4.4814 \\
Nitrogen & 2.5 & 13.481 \\
Carbon & 22.6 & 5.576 \\
Calcium & 1.43 & 0.41 \\
Boron-10 & - & 3835 \\
\hline
\end{tabular}

\section{Neutron sources}

The neutron source of this study is the Kartini Reactor. Neutrons are passed through a conceptually designed collimator. The conceptual design of the collimator on the Kartini Reactor thermal column is made from several materials [12]. The Kartini Reactor (TRIGA MARK-II Reactor), located in the Center of Research on Pure and Instrumentation Materials (PPBMI)-BATAN Yogyakarta, is one of three nuclear research reactors in Indonesia [4]. The Kartini reactor with the presence of the Lazy Susan, pneumatic, beam ports as well as a thermal column facility can be used as a means for irradiation for neutron activation analysis, the gamma irradiation for radiation chemistry, and neutron radiography as well as for basic research in connection to the Boron Neutron Capture Therapy.

\subsection{Radiation Interaction with Matter}

Radiation is defined as emission and propagation of energy through the matter or space in the form of electromagnetic waves or particle decay of a radioactive substance emitting charged particles. Charged particle radiation can be detected by utilizing the interaction of radiation with matter [13].

\subsection{Neutron Interaction with Matter}

Neutron interaction with matter can be broadly divided into two types, scattering or absorption. A more detailed description of the various reactions is described as follows.

\subsubsection{Scattering}

Scattering is a collision of neutrons to an atomic nucleus that is almost always in a state of quiescent or ground state. It has the lowest energy of an atom in a normal circumstance. The neutron out of the core and the core in a state leaving its ground state.

There are two kinds of neutron scattering, elastic scattering and inelastic scattering. Elastic scattering is when the neutrons are scattered by the atomic nuclei because the state of the system remains unchanged. Inelastic scattering occurs when the atomic nuclei that have been pounded by neutrons are in an excited state. Thus, the atom has more energy than during its ground state. The collision energy is stored in the nucleus so the interaction is endothermic.

\subsubsection{Capture / Absorption}

Capture or absorption reaction happens when the atomic nuclei absorbs neutrons then transmit one or more so-called captured gamma rays. Capture reaction is symbolized by the exothermic interaction $(\mathrm{n}, \gamma)$, while radiation absorption is symbolized as (n, $\alpha)$.

\subsection{Gamma Interaction with Matter}

Gamma ray is a photon produced by unstable nuclide. There are many possible interactions between gamma and matter, but the most important interactions are photoelectric effect, Compton scattering, and pair production.

\subsubsection{Photoelectric Effect}

Photoelectric effect is an interaction of photons with strong bound electrons in atoms, that is electrons in the inner shell of an atom, usually at surface $\mathrm{K}$ or L. Photons will pound these electrons and the electrons that bind strongly because the electrons will absorb the entire energy of the photons. The result is that electrons are emitted out of the atom with kinetic energy equal to the difference between the energy of the photons and the electrons' connective power.

\subsubsection{Compton Scattering}

Compton scattering occurs when X-rays unit of energy in the event of light deflected from its original path by interaction with an electron. The electrons are rejected, excluded from the position of the orbital and the amount of energy depends on the corner or corner in not spread and the nature of the medium that spreads, because the unit energy X-rays in a diffuse light has less energy, longer wavelengths and less penetration compared to the unit of energy in light.

\subsubsection{Pair Production}

Pair production is an interaction between a photon and an atomic nucleus. It occurs when the energy of a photon is at $1.022 \mathrm{MeV}$ or above. Photon energy is absorbed completely, and the resulting photon becomes an electron-positron pair. The rest of the mass of each particle of electron is equivalent to $0.511 \mathrm{MeV}$. 


\subsection{Dosimetry}

There are four components of the dose that need to be considered.

\subsubsection{Gamma Dose (D $\gamma)$}

Gamma dose is the accumulation of thermal neutron which is captured by the hydrogen reaction rate. The reaction is between hydrogen-1 in body tissues and thermal neutrons. This reaction is equal from rate of hydrogen-2. The result will be a gamma particle which has an energy of $2.33 \mathrm{MeV}$. The reaction is shown equation (1).

$$
{ }_{1}^{1} \mathrm{H}+{ }_{1}^{1} n(0.025 \mathrm{MeV}) \rightarrow{ }_{1}^{1} \mathrm{H}+\gamma(2.33 \mathrm{MeV})
$$

Gamma dose rate from hydrogen reaction is

$$
\begin{gathered}
D_{\gamma}=\dddot{R} \times \varphi \times \Delta \frac{G y}{\mathrm{~s}} \\
\Delta=1.6 \times 10^{-13} \times 2.33 \frac{\mathrm{MeV}}{\gamma}=3.568 \times 10^{-13} \frac{\mathrm{Gy} / \mathrm{s}}{\mathrm{Bq} / \mathrm{kg}}
\end{gathered}
$$

where

$\Phi=$ absorbed dose fraction of gamma

$\Delta=$ absorbed dose rate coefficient/ specific activity.

$((\mathrm{Gy} / \mathrm{s}) /(\mathrm{Bq} / \mathrm{kg}))$

\subsubsection{Neutron Scattering Dose (Dn)}

The neutrons produced by the reactor are not only thermal neutrons but also fast neutrons. The interaction between neutron and matter can produce recoil and photon radiation. The interaction impact to be scattering reaction. The neutron flux characteristics at the beam outlet depend mainly on the neutron cross section data of the materials used. Resonance scatters are promising materials for epithermal neutron beams [14].

\subsubsection{Proton Dose (DP)}

Proton dose is determined from the interaction of nitrogen-14 which capture neutrons, generating carbon-14 and $0.66 \mathrm{MeV}$ proton in process. The reaction is shown in equation (2).

$$
{ }_{7}^{14} \mathrm{~N}+{ }_{0}^{1} n(0.025 \mathrm{MeV}) \rightarrow{ }_{6}^{14} \mathrm{C}+{ }_{1}^{1} p(0.66 \mathrm{MeV})
$$

To calculate the proton dose, equation (3) is used.

$$
D_{p}=\frac{\phi N_{N} \sigma_{N} Q \times 1,6 \times 10^{-13} \mathrm{~J} / \mathrm{MeV}}{1 \frac{\mathrm{J} / \mathrm{kg}}{G y}}
$$

where

$\mathrm{D}_{\mathrm{p}}=$ proton dose rate $(\mathrm{Gy} / \mathrm{s})$

$\Phi=$ thermal neutron flux $\left(\mathrm{n} / \mathrm{cm}^{2} \mathrm{~s}\right)$

$\mathrm{N}_{\mathrm{N}}=$ amount of nitrogen atoms/tissue weight (atom $/ \mathrm{kg})$
$\sigma_{\mathrm{N}}=$ Nitrogen microscopic cross section $\left(\mathrm{cm}^{2}\right)$

$\mathrm{Q}=$ particle energy $(\mathrm{MeV})$

\subsubsection{Boron Dose (DB)}

The boron dose calculates the thermal neutrons captured by boron-10, which interaction produces lithium-7 and $2.33 \mathrm{MeV}$ alpha particle. The reaction between thermal neutrons and boron-10 in tissue have the highest probability of happening because boron has a high thermal neutron capture cross section when compared to another element. The reaction is in provided in Equation 1. To calculate the dose rate from this interaction, equation (4) is used.

$$
\mathrm{D}_{\mathrm{B}}=\frac{\phi N_{B} \sigma_{B} Q \times 1.6 \times 10^{-13} \mathrm{~J} / \mathrm{MeV}}{1 \frac{J / K g}{G y}}
$$

where

$\mathrm{D}_{\mathrm{B}}=$ alpha dose rate $(\mathrm{Gy} / \mathrm{s})$

$\Phi=$ thermal neutron flux $\left(\mathrm{n} / \mathrm{cm}^{2} \mathrm{~s}\right)$

$\mathrm{N}_{\mathrm{B}}=$ amount of Boron atoms/ tissue weight (atom $/ \mathrm{kg}$ )

$\sigma_{\mathrm{B}}=$ Boron microscopic cross section $\left(\mathrm{cm}^{2}\right)$

$\mathrm{Q}=$ particle energy $(\mathrm{MeV})$

\subsubsection{Total Dose}

The total dose received by the organ is based on equation (5).

$$
\mathrm{D}=\mathrm{w}_{\mathrm{B}} \mathrm{D}_{\mathrm{B}}+\mathrm{w}_{\mathrm{p}} \mathrm{D}_{\mathrm{p}}+\mathrm{w}_{\mathrm{n}} \mathrm{D}_{\mathrm{n}}+\mathrm{w}_{\gamma} \mathrm{D}_{\gamma}
$$

where

$\mathrm{D}_{\mathrm{B}}$ : boron absorbed doses respectively

$\mathrm{D}_{\mathrm{p}}$ : Thermal absorbed doses respectively

$\mathrm{D}_{\mathrm{n}}$ : Fast absorbed doses respectively

$\mathrm{D}_{\gamma}$ : gamma absorbed doses respectively

$\mathrm{w}_{\mathrm{B}}$ : weight factor for alpha particles are 3.8 (tumor) and 1.35 (normal tissues)

$\mathrm{W}_{\mathrm{p}}$ : weight factor for proton is 3.2

$\mathrm{W}_{\mathrm{n}}$ : weight factor for neutron is 3.2

$\mathrm{w}_{\gamma}$ : weight factor for gamma is 1

Weight factor is the coefficient to show the damaging capability from absorbed radiation. The value is different for each type of radiation and is influenced by the target tissue radio sensitivity.

\section{METHODOLOGY}

\subsection{MCNPX (Monte Carlo N-Particle Extended) Program}

MCNPX is a program to simulate particle transport including the theoretical experimentation 
developed at Los Alamos National Laboratory (LANL) and distributed by Radiation Safety Information Computational Center (RSICC) at Oak Ridge National Laboratory [15]. MCNPX program is used to determine the neutron flux in the air. A strong source of photon is converted to particles per second by multiplier factor of $1 \times 10^{-9} \mathrm{c} / \mathrm{s}$.

\subsection{Geometry Modeling in MCNPX}

The phantom of the experiment is water which size represent the size of a liver. To generate the geometry, the coding is made in the notepad. The code to generate the object needs 3 blocks of card.

The cell card block defines the area of a selected cell with the material used which is defined on the data card. Concentration of material is also included. In this block, the material parameters in a cell are set.

The surface card generates the form of the object. The water phantom was modeled with a size approximately similar with liver in a cube form. The dimension is $7.5 \times 7.5 \times 7.5 \mathrm{~cm}$. The cancer cell is included in layer 3 of the phantom; there is a GTV (gross tumor volume) with a radius of $1.5 \mathrm{~cm}$, a CTV (clinical tumor volume) with a radius of $1.75 \mathrm{~cm}$, and a PTV (planning tumour volume) with a radius of $2 \mathrm{~cm}$. The cancer cell is in a spherical form. The neutron source is set to the left side of the phantom. Around the outside of the phantom, a sphere containing air is generated. Outside of the cancer cell is a water-containing cube. On the left side of the cube is the tip of the Kartini reactor, the neutron source defined as a radial plate with neutron direction in the $\mathrm{x}$-axis, directed into the cancer cell.

The material card defines the material used in the cell. Innermost cell is GTV which contains cancer cell with boron in full concentration. The second layer is the CTV which contains a cancer cell with half boron concentration in the GTV. The third layer is the PTV which contains a normal cell with one tenth boron concentration in the GTV.

\subsection{Tally}

Tally is the information required to obtain the neutron flux. The cell selected to calculate the neutron flux is the cancer cell in layer 3 of GTV, PTV, CTV, and the water phantom. MCNPX provides several kinds of tally as in Table 3 .
Table 3. Tally code to select the parameters which are offered in MCNPX

\begin{tabular}{cccc}
\hline Tally & Particle Mode & Description & Unit \\
\hline F1 & $: \mathrm{N},: \mathrm{P},: \mathrm{E}$ & $\begin{array}{c}\text { Current through } \\
\text { surface } \\
\text { Average flux } \\
\text { through surface } \\
\text { Average flux } \\
\text { through cell }\end{array}$ & $\begin{array}{c}\text { Particle } \\
\text { Particle/ } \\
\mathrm{cm}^{2} \\
\text { Particle/ } \\
\mathrm{cm}^{2}\end{array}$ \\
F4 & $: \mathrm{N},: \mathrm{P},: \mathrm{E}$ & $: \mathrm{N},: \mathrm{P},: \mathrm{E}$ & $\begin{array}{c}\text { Farticle/ } \\
\mathrm{cm}^{2}\end{array}$ \\
F5a & $: \mathrm{N},: \mathrm{P}$ & $\begin{array}{c}\text { Average energy } \\
\text { disposition through } \\
\text { cell }\end{array}$ & $\mathrm{MeV} / \mathrm{g}$ \\
F6 & $: \mathrm{N},: \mathrm{P},: \mathrm{N}, \mathrm{P}$ & $\begin{array}{c}\text { Fission energy } \\
\text { disposition in cell } \\
\text { Energy pulse } \\
\text { distribution on } \\
\text { detector }\end{array}$ & $\mathrm{MeV} / \mathrm{g}$ \\
F7 & $: \mathrm{N}$ & $\mathrm{Pulse}$ \\
F8 & $: \mathrm{N},: \mathrm{P},: \mathrm{E},: \mathrm{P}, \mathrm{E}$ & \multicolumn{3}{c}{} \\
\hline
\end{tabular}

To determine the neutron flux through the cell, f4 was used.

\subsection{Calculation of dosimetry}

To calculate the dose is by calculating the sum of the boron dose, proton dose, neutron dose, and gamma dose that are simulated and then calculated using the aforementioned equation.

Using MCNPX, the problem must be identified first. In this research, the dose estimation for cancer therapy needs to be known before it is applied to the patient. So, to the dose simulation must be done in a phantom. The phantom used here is wateras a substitute for human body.

After obtaining the number of neutron flux in the cancer cell, then the dose of gamma, neutron, proton and boron was calculated to obtain the total dose.

\section{RESULTS AND DISCUSSION}

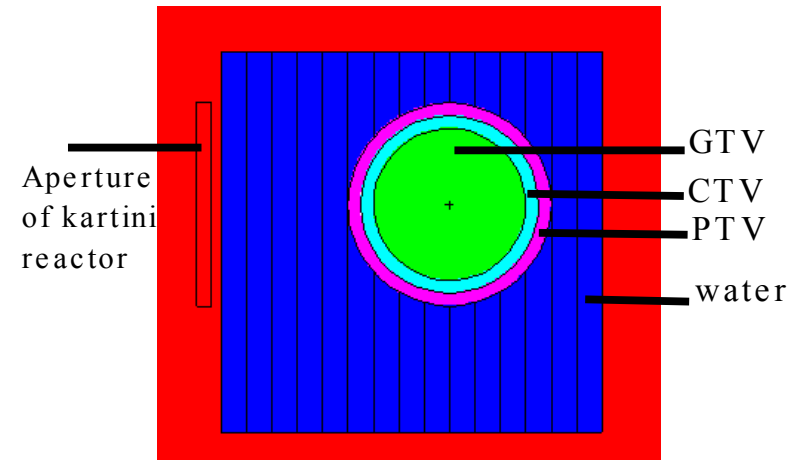

Figure 2. Geometry design of cancer cell in water phantom with MCNPX 
The phantom is built in a cubic shape divided in 30 sections with intervals of $0.5 \mathrm{~cm}$ for each surface. This is aimed to determine the flux through the water in each depth, in order to learn the characteristic of neutron through the cell.

\subsection{Flux distribution}

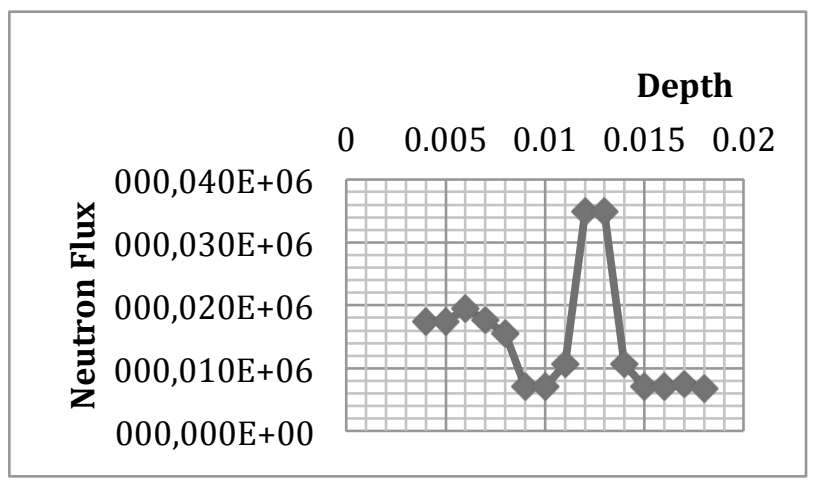

Figure 3. Flux distribution in every depth of the phantom.

Neutron flux which comes out from the source is $1.14228 \times 10^{7}$ neutron $/ \mathrm{cm}^{2}$.s. Flux distribution in water phantom cell decreases through the depth of the phantom apart from the cancer cell. Neutron flux in the cancer cell increases because the cancer cell contains boron, with concentration of $10 \%$ in PTV, 50\% in CTV, and $100 \%$ in GTV. The highest neutron flux is in the GTV cell as it contains the highest boron concentration. Therefore, the highest number of neutrons are captured in GTV.

\subsection{Total Dose}

Total dose is obtained by totaling the weight of particle, multiplied to the proton dose, neutron dose, gamma dose, and alpha dose. Giving $20 \mu \mathrm{g} / \mathrm{g}$ tissue we calculated the dose for each cell (in $\mathrm{Gy} / \mathrm{s}$ ).

Table 4. Result of the calculation gamma dose, proton dose, alpha dose, and neutron dose

\begin{tabular}{lcccc}
\hline & $\mathbf{D}_{\gamma}$ & $\mathbf{D}_{\mathrm{p}}$ & $\mathbf{D}_{\boldsymbol{\alpha}}$ & $\mathbf{D}_{\mathbf{n}}$ \\
\hline GTV & 6.3175 & $1.98 \mathrm{E}-$ & 1.3755 & 6.5043 \\
& $3 \mathrm{E}-11$ & 05 & $9 \mathrm{E}-07$ & $\mathrm{E}+13$ \\
$\mathbf{C T V}$ & 1.8665 & $1.98 \mathrm{E}-$ & 3.4562 & 1.6342 \\
& $3 \mathrm{E}-11$ & 05 & $\mathrm{E}-08$ & $\mathrm{E}+13$ \\
PTV & 1.4235 & $1.98 \mathrm{E}-$ & 7.8422 & 3.7081 \\
& $4 \mathrm{E}-11$ & 05 & $3 \mathrm{E}-09$ & $\mathrm{E}+12$ \\
Water & 2.4930 & $1.98 \mathrm{E}-$ & 1.2641 & 5.9774 \\
& $0 \mathrm{E}-11$ & 05 & $6 \mathrm{E}-10$ & $\mathrm{E}+10$ \\
& & & & \\
\hline
\end{tabular}

According to previous study, the minimum dose to destroy cancer cell is $30 \mathrm{~Gy}$. To obtain the effective irradiation time to reach $30 \mathrm{~Gy}$, the following formula is used. irradiation time $=\frac{\text { Total dose rate }(G y . s)}{30 \mathrm{~s}}$

Table 5. Total dose rate and irradiation time to reach 30

\begin{tabular}{lccc}
\multicolumn{4}{c}{ Gy. } \\
\hline & $\begin{array}{c}\text { Total Dose } \\
\text { Rate (Gy.s) }\end{array}$ & $\%$ & $\begin{array}{c}\text { Irradiation } \\
\text { time }\end{array}$ \\
\hline GTV & $2.0814 \mathrm{E}+14$ & $76.38 \%$ & $1.4414 \mathrm{E}-13$ \\
CTV & $5.2295 \mathrm{E}+13$ & $19.19 \%$ & $5.7367 \mathrm{E}-13$ \\
PTV & $1.1866 \mathrm{E}+13$ & $4.35 \%$ & $2.5283 \mathrm{E}-12$ \\
& & & $1.5684 \mathrm{E}-10$ \\
\hline
\end{tabular}

GTV captured more neutrons than the other cells, as much as $76.38 \%$ of total neutron flux. This is because GTV contains the highest concentration of boron. GTV needs an irradiation time of $1.4414 \mathrm{E}-13 \mathrm{~s}$. This extremely short time is enough to destroy cancer cell in liver.

\section{CONCLUSION}

BNCT is promising as one form of cancer therapy due to the reasons that it works selectively and does not have an adverse effect for the normal tissue. Water can represent the soft tissue of humans and can be used as an experimental object of research. Total dose rate to destroy the cancer cell in GTV is $2.0814 \times 10^{14}$ Gy.s $(76.38 \%)$ with irradiation time of $1.4414 \times 10^{13} \mathrm{~s}$. In PTV it is $5.2295 \times 10^{13}$ Gy.s $(19,19 \%)$ with irradiation time of $5.7367 \times 10^{-13}$ s. In CTV it is $1.1866 \times 10^{13}$ Gy.s $(4,35 \%)$ with irradiation time of $2.5283 \times 10^{-12} \mathrm{~s}$. lastly, in the water, it is $1.9128 \mathrm{E}+11 \mathrm{~Gy} . \mathrm{s}(0,07 \%)$ with irradiation time of $1.5684 \times 10^{-10} \mathrm{~s}$. The irradiation time is extremely short because the modeling is based on water phantom not in phantom human body.

\section{ACKNOWLEDGMENT}

The authors would like to thank PSTABATAN Yogyakarta for allowing the author to do the research. Thanks to Dr. Zaenuri as the Dean of Mathematics and Natural Sciences Faculty, State University of Semarang for supporting the author do the research. Thanks to Laely and Imam from UNNES and all the colleagues in the engineering room of PSTA-BATAN to do our research together. 


\section{REFERENCES}

1. National Cancer Institute. What is cancer? Understanding Cancer. Accesed form: https://www.cancer.gov/aboutcancer/understan ding/what-is-cancer, 2 September 2019

2. Shahban, M., Hussain, B., Mehmood, K., \& Rehman, S. U.Estimation of peripheral dose from Co60 beam in water phantom measured in Secondary Standard Dosimetry Laboratory, Pakistan. Reports of Practical Oncology and Radiotherapy, 22(3), 212-216. 2017

3. Rosidah, S., Sardjono, Y., \& Sumardi, Y.. Dose Analysis of Boron Neutron Capture Therapy (BNCT) At Skin Cancer Melanoma Using MCNPX With Neutron Source from Thermal Column of Kartini. Indonesian Journal of Physics and Nuclear Applications, 2(3), 111-123. 2017

4. [5] Satoh, D., Kajimoto, T., Shigyo, N., Itashiki, Y.,

5. Imabayashi, Y., Koba, Y., Uozumi, Y. (2016). Distributions of neutron yields anddoses around a water phantom bombardedwith 290$\mathrm{MeV} /$ nucleon and 430-MeV/nucleon carbon ions. Nuclear Instruments and Methods in Physics Research, Section B: Beam Interactions with Materials and Atoms, 387,10-19.

6. Pozzi, E. C. C., Cardoso, J. E., Colombo, L. L., Thorp, S., Hughes, A. M., Molinari, A. J., Schwint, A. E.Boron neutron capture therapy (BNCT) for liver metastasis: Therapeutic efficacy in an experimental model. Radiation and Environmental Biophysics, 51(3). 2012.

7. Tesalonika, A. Dosimetry of in vitro and in vivo Trials in Thermal Column Kartini Reactor for Boron Neutron Capture Therapy (BNCT) facility by using MCNPX Simulator Code. Indonesian Journal of Physics and Nuclear Applications, 1(10), 63-72. 2016.
8. Sakurai, Y., Tanaka, H., Takata, T., Fujimoto, N., Suzuki, M., Masunaga, S., Maruhashi, A. Advances in boron neutron capture therapy (BNCT) at Kyoto University - From reactorbased BNCT to accelerator-based BNCT. Journal of the Korean Physical Society, 67(1),76-81. 2015.

9. IAEA Current status of neutron capture therapy. Vienna, Austria:International Atomic Energy Agency: 2001.

10. Hassanein, A. M., Hassan, M. H., Mohamed, N. M. A., \& Abou Mandour, M. A. (2018). An optimized epithermal BNCT beam design for research reactors. Progress in Nuclear Energy, 106 (May 2017), 455-464.

11. Nuclear Data Center JAEA.accesed form: https://wwwndc.jaea.go.jp/Labo/ncap.html.201 9

12. Ramadhan Valiant Gill S Balle.In Vivo Total Dose Analysis in Mice for BNCT Trial TRIGA Kartini Research Reactor Based Using PHITS. Indonesian Journal of Physics and Nuclear Application. 2019

13. Wicaksono, A. S., Widiharto, A., \& Sardjono, Y. (2016). Internal Dose Analysis for Radiation Worker in Cancer Therapy Based on Boron Neutron Capture Therapy with Neutron Source Cyclotron $30 \mathrm{MeV}$ Using Monte Carlo $\mathrm{N}$ Particle Extended Simulator. Indonesian Journal of Physics and Nuclear Applications, 2(2), 91-100.

14. Paul Sherer Institut .Neutron Matter Interaction.

Accesedform:https://www.psi.ch/en/niag/neutr on-interaction-with-matter.2019

15. Aghara, S. K., Sriprisan, S. I., Singleterry, R. C., \& Sato, T. (2015). Shielding evaluation for solar particle events using MCNPX, PHITS and OLTARIS codes. Life Sciences in Space Research, 4, 79-91. 
This page is intentionally blank 